\title{
Optimal reservoir operation in electric power market transaction model
}

\author{
Yingqin Chen \\ Department of Civil Engineering, Hohai University Wentian College, Ma'anshan, China \\ chenyingqin_nj@163.com
}

\begin{abstract}
Keywords: Power market; Reservoir operation; Particle swarm optimization algorithm; Improved particle swarm optimization algorithm; Peak and off-peak electricity price.

Abstract. Electric power market transaction is one of the important measures for the reform of the electric power system in China. In this paper, the characteristics of the optimal reservoir scheduling in the electric power market transaction model are analyzed, and the optimal operation model of the reservoir is established. Based on the standard particle swarm optimization, the improved particle swarm optimization algorithm is proposed, which is based on the improvement of the inertia factor, the acceleration factor and the iteration speed. Taking Qingxi Reservoir, which locates in Meizhou City, Guangdong Province, as an example, the annual benefits under the off-peak electricity price in the dry, normal and wet year are increased by $1.42 \%, 19.49 \%$ and $15.85 \%$ respectively. The results show that the annual benefit based on the off-peak electricity price of hydropower station is significantly higher than that of monovalent system. The study results can be used to solve electric power market transaction mode water reservoir optimization dispatching strategy.
\end{abstract}

\section{Introduction}

As a kind of clean renewable energy, hydropower has important advantages in the sustainable development of electric power industry in the future, and it is very important for the safe and stable operation of the whole power network. Under the background of the electric power market, the power generation will be changed from the plan to the market as the center, hydropower station scheduling can be adapted to the development requirements with the maximum power generation efficiency, it has become an inevitable trend to implement the policy of the electricity price and the price of the Internet, so it is very important to study the optimal operation of reservoir in the research of market trading mode.

Foreign power market is mainly in order to adapt to the reform of the political and energy industry, the success of the UK electricity market reforms to make the country to see the great potential of the market system, after entering 2000, Latin American countries, the United States, the European Union, Asian countries and other countries in the power market reform. Abroad in the electricity market, hydropower station scheduling research has achieved some results: in 2008, Vicuna considered the impact of peak valley electricity price on the reservoir operation, in 2009 Madani and Lund to explore the impact of the different monthly electricity price of electricity generated ${ }^{[1]}$. Some results have been obtained in the research of reservoir operation in the electricity market environment. In 1997, Wan Yonghua first proposed the model of the hydropower station scheduling model with the peak and valley time price. In 2012, Feng Quanlong and Zhang Yuhui put forward the long-term optimal operation model of hydropower station under the condition of wet and dry condition, and achieved remarkable results in the practical application, Lay the foundation for hydropower scheduling under peak and off-peak electricity price ${ }^{[2]}$. In $2014 \mathrm{Li} \mathrm{Jia}$, Ma Guangwen, Wang Li, et al. Research on the electricity market trading environment of the annual power generation plan to develop the problem.

With the reform of electric power market and the scale of power system, China's electric power industry is gradually implementing market mechanism, and hydropower is bound to market, in accordance with the principle of "fair, fair and open" to participate in the competition ${ }^{[3-4]}$. With the implementation of the policy of "bidding" and the change of the load demand of hydropower station itself, how to set up a new model which is based on the power market environment, which is a new research topic, is a new research topic ${ }^{[5-8]}$. 
This paper mainly introduces the system optimal regulation of hydropower station reservoir model under the seasonal price, in reservoir scheduling model has been added to the price influence factors, and consider a number of constraints, for peak and off-peak electricity price, the according to wet water period and dry water period price different for reasonable reservoir optimization dispatching under known amount of water for the whole year. There are many methods to solve this problem, such as dynamic programming algorithm, genetic algorithm, ant colony algorithm, particle swarm optimization (PSO) rapid development in recent years, wide application field, has become the research hotspot in the field of international evolution computing. PSO algorithm has been widely used in reservoir operation due to its simple principle, fast convergence and strong versatility ${ }^{[9-11]}$. In this paper, the particle swarm optimization algorithm is used to solve the basic particle swarm optimization algorithm, which improves the calculation accuracy and convergence speed. Finally, the optimal operation of hydropower station with the optimal power generation is solved by using the case of Qingxi Reservoir.

\section{Reservoir optimal operation model in electricity market}

In the monovalent system, because the price is fixed, and plant proceeds is generating capacity and price of the product, that is to say, the biggest benefit is actually generating maximum amount, due to the existence of price difference, the maximum power output doesn't mean the maximum benefit. At present a lot of reservoir optimal operation with the maximum generating capacity is not to solve the above mentioned problems, so the optimal scheduling of reservoir considering time sharing price factor is a new research topic ${ }^{[12-16]}$.

(1) objective function

Output of hydropower station in the case of water has been set, according to the maximum power output as a criterion for the optimization goal:

$$
F=\operatorname{Max} \sum_{i}^{T}\left(A \cdot Q_{i} \cdot H_{i} \cdot T_{i}\right)
$$

At the time of the electricity price $B_{i}, i=1,2, \ldots, T$ given, the annual profit of the hydropower station is determined by the sum of the product of the electricity price and the net quantity in the year:

$$
M=\operatorname{Max} \sum_{i}^{T}\left(A \cdot Q_{i} \cdot H_{i} \cdot T_{i} \cdot B_{i}\right)
$$

In the formula: $A$ is output coefficient for power station; $Q_{i}$ is water diversion for power station in the $i$ period; $H i$ is average power generation net head for power station in the $i$ period; $T_{i}$ is number of power generation hours for power plants in the $i$ period; $B_{i}$ is time sharing price; $M$ is total power generation for a period of time.

(2) constraint condition

(1) Water balance constraint:

$$
V_{i}=V_{i-1}+Q_{\gamma i}-Q_{\delta i}-Z F_{i}-L_{i}
$$

In the formula: $V_{i}$ is water storage capacity of reservoir at the end of $i$ period, $\mathrm{m}^{3} ; V_{i-1}$ is water storage capacity of reservoir at the begin of $i$ period, $\mathrm{m} 3 ; Q_{\gamma i}$ is reservoir inflow in the $i$ period, $\mathrm{m}^{3} ; Q_{\delta i}$ is water discharge for reservoir in the $i$ period, $\mathrm{m} 3 ; Z F_{i}$ is evaporation of water in the $i$ period, $\mathrm{m}^{3} ; L_{i}$ is leakage loss in the $i$ period, $\mathrm{m}^{3}$.

(2) Capacity limit:

$$
V_{s} \leq V_{i} \leq V_{z}
$$


(3) Power diversion flow limit:

$q_{i \leq} q_{\max } ; q_{i} \geq q_{\min }$

In the formula: $q_{i}$ is diversion water flux in the $i$ period, $\mathrm{m}^{3} / \mathrm{s} ; q_{\max }$ is the maximum diversion water flux in the $i$ period, $\mathrm{m}^{3} / \mathrm{s} ; q_{\min }$ is the minimum diversion water flux in the $i$ period, $\mathrm{m}^{3} / \mathrm{s}$.

(4) Output constraint of power station:

$N_{i} \leq N_{\max }$

In the formula: $N_{i}$ is output in the $i$ period, $\mathrm{kw} ; N_{\max }$ is the maximum output in the $i$ period, $\mathrm{kw}$.

$$
N_{i}=\frac{F_{i}}{T_{i}}
$$

(5) All parameters are not negative.

\section{Improved particle swarm optimization algorithm}

\section{The principle of Particle Swarm Optimization Algorithm}

PSO algorithm is a kind of intelligent optimization algorithm, which is based on the study of birds flying. In the space of $\mathrm{D}$ dimension, there is a group of particles, the position of the $i$ particle is $x_{i}=\left(x_{i 1}, x_{i 2}, \mathrm{~L}, x_{i d}\right)$, the flight speed is $v_{i}=\left(v_{i 1}, v_{i 2}, \mathrm{~L}, v_{i d}\right)$, the optimal position of the whole particle swarm iteration to the $\mathrm{h}$ time is $P_{g d}=\left(P_{i 1}, P_{i 2}, \mathrm{~L}, P_{i d}\right)$, the basic formula is as follows:

$$
\begin{aligned}
& v_{i d}^{(k+1)}=\omega v_{i d}^{(k)}+c_{1} r_{1}^{(k)}\left(P_{i d}^{(k)}-x_{i d}^{(k)}\right)+c_{2} r_{2}^{(k)}\left(P_{g d}^{(k)}-x_{i d}^{(k)}\right) \\
& x_{i d}^{(k+1)}=x_{i d}^{(k)}+v_{i d}^{(k+1)}
\end{aligned}
$$

In the formula: $c_{1}, c_{2}$ is acceleration coefficient; $r_{1}, r_{2}$ is random number between $[0,1]$; $\omega$ is inertia factor and weight of control speed.

\section{Improved particle swarm optimization algorithm}

(1) Clerc and Kennedy propose a compression factor PSO algorithm, which can be used to ensure the convergence of the PSO algorithm by selecting the appropriate parameters of the algorithm ${ }^{[17]}$.

$$
\begin{aligned}
& v_{i d}^{(k+1)}=\chi\left\{\omega v_{i d}^{(k)}+c_{1} r_{1}^{(k)}\left[P_{i d}^{(k)}-x_{i d}^{(k)}\right]+c_{2} r_{2}^{(k)}\left[P_{g d}^{(k)}-x_{i d}^{(k)}\right]\right\} \\
& \chi=\frac{2}{\left|2-\varphi-\sqrt{\varphi^{2}-4 \varphi}\right|}, \varphi=c_{1}+c_{2}, \varphi>4
\end{aligned}
$$

$\chi$ is Compression factor in the formula.

In general, the initial value of the initial value is 0.9 and the number of iterations with the increase of diminishing to 0.4 , the selection of inertia factor $\omega$ is the first to focus on the global search to quickly converge to a specific area of the search space, and then use the local fine search to obtain a more accurate solution ${ }^{[18]}$, using evolutionary factor $f$ to adjust the weight change, the specific formula is as follows:

$$
\omega(f)=\frac{1}{1+1.5 e^{-2.6 f}} \in[0.4,0.9], \forall f \in[0,1]
$$

In order to ensure the smooth solution of the algorithm, $c_{1}+c_{2}$ must be more than 4 . In this paper, the formula (12) is used to calculate it. 


$$
c_{i}=\frac{c_{i}}{c_{1}+c_{2}} * 4.0, i=1,2 . c_{1}, c_{2} \in[1.5,2.5]
$$

(2) The particle swarm optimization algorithm is combined with the natural selection principle of genetic algorithm, and the particle swarm optimization algorithm based on natural selection is obtained. In the iteration process, the whole particle swarm is sorted according to the fitness value, and the better half of the particle's position and velocity is replaced by half of the particle and the historical optimal value of each individual ${ }^{[19]}$.

According to the improved particle swarm algorithm, the calculation steps of the five PSO algorithm are used to test several test functions:

(1) Rastrigin function:

$$
f(\stackrel{r}{x})=\sum_{i=1}^{l}\left(10+x_{i}^{2}-10 \cos \left(2 \pi x_{i}\right)\right)
$$

In the formula, $-5.12 \leq x_{i} \leq 5.12$, its overall advantage is $X=(0,0,0 \mathrm{~L}, 0)$, global extreme value is 0 .

(2) DeJong function:

$$
f(\stackrel{r}{x})=\sum_{i=1}^{l} x_{i}^{2}
$$

In the formula, $-20 \leq x_{i} \leq 20$, its overall advantage is $X=(0,0,0 \mathrm{~L}, 0)$, global extreme value is 0 .

(3) Sphere function:

$$
f(\stackrel{r}{x})=\sum_{i=1}^{l} x_{i}^{2}
$$

In the formula, $-50 \leq x_{i} \leq 50$, its overall advantage is $X=(0,0,0 \mathrm{~L}, 0)$, global extreme value is 0 .

(4) Griewank function:

$$
f(\stackrel{r}{x})=1+\sum_{i=1}^{l}\left(\frac{x_{i}^{2}}{4000}\right)-\prod_{i=1}^{l} \cos \left(\frac{x_{i}}{2 \sqrt{i}}\right)
$$

In the formula, $-600 \leq x_{i} \leq 600$, its overall advantage is $X=(0,0,0 \mathrm{~L}, 0)$, global extreme value is 0 .

(5) Rosenbrock function:

$$
f(\stackrel{r}{x})=\sum_{i=1}^{l-1}\left(100\left(x_{i+1}-x_{i}^{2}\right)^{2}+\left(x_{i}-1\right)^{2}\right)
$$

In the formula, $-100 \leq x_{i} \leq 100$, its overall advantage is $X=(1,1,1 \mathrm{~L}, 1)$, global extreme value is 0 .

Table 1 Test results

\begin{tabular}{cccccc}
\hline algorithm & Rastrigin & DeJong & Sphere & Griewank & Rosenbrock \\
\hline Particle swarm optimization algorithm & $1.07 \mathrm{E}+02$ & $4.35 \mathrm{E}+02$ & $3.70 \mathrm{E}+02$ & $2.61 \mathrm{E}+07$ & $1.39 \mathrm{E}+01$ \\
Calman group algorithm & $5.33 \mathrm{E}+01$ & $4.61 \mathrm{E}+00$ & $4.72 \mathrm{E}+00$ & $3.28 \mathrm{E}+03$ & $9.96 \mathrm{E}-01$ \\
Improved particle swarm optimization algorithm & $7.91 \mathrm{E}+00$ & $1.29 \mathrm{E}-02$ & $1.90 \mathrm{E}-01$ & $1.75 \mathrm{E}-01$ & $6.88 \mathrm{E}-01$ \\
\hline
\end{tabular}

Improved particle swarm optimization algorithm parameter settings: $\omega=0.9, c_{1}=c_{2}=2$, the number of population is 50, iteration 2000 times, the results of the test 20 times to get the average value of Table 1 , and the rest of the results from the literature ${ }^{[20]}$. The results obtained from the test function fully prove that the improved particle swarm algorithm is superior to other algorithms in this paper. 


\section{Case study}

Qingxi Hydropower Station is located in Guangdong big town, $40 \mathrm{~km}$ from the Dapu County, is the second cascade hydropower station of the tributary from the Hanjiang River to Tingjiang River, dam over the river basin area of $9157 \mathrm{~km}^{2}$, the normal high water level for $7.3 \mathrm{~m}$, corresponding storage capacity for 6008 million $\mathrm{m}^{3}$. The average annual runoff of the Qingxi reservoir is 87.4 million $\mathrm{m}^{3}$, the average annual rainfall is $1600 \mathrm{~mm}$, the average inflow is $277 \mathrm{~m}^{3} / \mathrm{s}$, the main function of this project is to generate electricity, not to assume the downstream flood control.

According to the 1951 April to 2012 March a total of 62 years of Qingxi reservoir of natural runoff and annual runoff calculation results, selecting three design frequency approximately year with wet year $(\mathrm{P}=25 \%)$, normal years $(\mathrm{P}=50 \%)$, dry years $(\mathrm{P}=75 \%)$, respectively in 2010, 2005 and 2003, selected representing actual annual natural runoff are shown in Table 2.

Table 2 Typical hydrological year natural runoff

\begin{tabular}{cccc}
\hline & Table 2 Typical hydrological year natural runoff & Unit: $\mathrm{m}^{3} / \mathrm{s}$ \\
\hline Inflow rates & Representative year & Natural runoff \\
\hline $25 \%$ & 2010 & 3968.3 \\
$50 \%$ & 2005 & 3078.3 \\
$75 \%$ & 2003 & 2595.4 \\
\hline
\end{tabular}

The monovalent system does not consider the price factor of the influence that price is a constant, and the price under peak and off-peak electricity price, due to wet dry period of natural runoff, rainfall, runoff, etc. some factors, the electricity price for a change. Due to the variation in the price in different periods of computational complexity, in order to facilitate the calculation and examples of this price is simplified and the monovalent system under the price as the price of normal water, $0.35 \mathrm{yuan} / \mathrm{kW} \cdot \mathrm{h}$, wet water period price downward float of $25 \%$, that of 0.26 yuan $/ \mathrm{kW} \cdot \mathrm{h}$, dry electricity prices floating $50 \%$, that of 0.53 yuan $/ \mathrm{kW} \cdot \mathrm{h}$. For the same year on the power grid, due to the wet and dry season tariff of different electricity price and lead to a plant's annual revenue generated significant differences. As an example, calculated by Qingxi Reservoir, improved particle swarm algorithm and basic particle swarm optimization algorithm in revenue comparison data are shown in Table 3, typical year number according to the different valuation system by using an improved particle swarm algorithm to calculate annual power generation benefit, specific data is shown in Table 4.

Table 3 Annual income comparison table of different algorithms

\begin{tabular}{ccccccc}
\hline \multirow{2}{*}{ algorithm } & \multicolumn{2}{c}{ monovalent system income (100 million yuan) } & \multicolumn{2}{c}{ peak and off-peak electricity price(100 million yuan) } \\
\cline { 2 - 6 } & dry years & normal years & wet year & dry years & normal years & wet year \\
\hline Particle swarm optimization algorithm & 2.803 & 2.756 & 3.280 & 2.838 & 3.301 & 3.793 \\
Improved particle swarm optimization algorithm & 2.814 & 2.766 & 3.284 & 2.855 & 3.312 \\
\hline
\end{tabular}

Table 4 Typical annual hydrological generating efficiency table

\begin{tabular}{|c|c|c|c|c|c|c|c|c|c|}
\hline \multirow{2}{*}{ Month } & \multicolumn{3}{|c|}{ generating capacity $\left(10^{4} \mathrm{MW} \cdot \mathrm{h}\right)$} & \multicolumn{3}{|c|}{ monovalent system income (100 million yuan) } & \multicolumn{3}{|c|}{ peak and off-peak electricity price (100 million yuan $)$} \\
\hline & dry years & normal years & wet year & dry years & normal years & wet year & dry years & normal years & wet year \\
\hline 4 & 8.64 & 8.69 & 8.69 & 0.30 & 0.30 & 0.30 & 0.22 & 0.23 & 0.23 \\
\hline 5 & 8.69 & 8.69 & 8.69 & 0.30 & 0.30 & 0.30 & 0.23 & 0.23 & 0.23 \\
\hline 6 & 8.69 & 8.69 & 8.69 & 0.30 & 0.30 & 0.30 & 0.23 & 0.23 & 0.23 \\
\hline 7 & 8.69 & 8.69 & 8.69 & 0.30 & 0.30 & 0.30 & 0.23 & 0.46 & 0.30 \\
\hline 8 & 3.90 & 8.69 & 8.69 & 0.14 & 0.30 & 0.30 & 0.21 & 0.46 & 0.30 \\
\hline 9 & 7.31 & 8.69 & 8.69 & 0.26 & 0.30 & 0.30 & 0.39 & 0.46 & 0.30 \\
\hline 10 & 2.64 & 8.69 & 7.13 & 0.09 & 0.30 & 0.25 & 0.14 & 0.46 & 0.38 \\
\hline 11 & 3.62 & 3.28 & 6.94 & 0.13 & 0.11 & 0.24 & 0.19 & 0.17 & 0.37 \\
\hline 12 & 2.14 & 5.28 & 7.63 & 0.07 & 0.18 & 0.27 & 0.11 & 0.28 & 0.40 \\
\hline 1 & 8.69 & 4.60 & 3.76 & 0.30 & 0.16 & 0.13 & 0.30 & 0.16 & 0.20 \\
\hline 2 & 8.69 & 1.38 & 7.51 & 0.30 & 0.05 & 0.26 & 0.30 & 0.05 & 0.40 \\
\hline 3 & 8.69 & 3.65 & 8.69 & 0.30 & 0.13 & 0.30 & 0.30 & 0.13 & 0.46 \\
\hline Total & 80.41 & 79.04 & 93.83 & 2.81 & 2.77 & 3.28 & 2.85 & 3.31 & 3.80 \\
\hline
\end{tabular}

From the analysis in Table 3 show that, for different typical hydrological years, improved particle swarm optimization algorithm in both monovalent system or in the wet and dry price system of annual 
revenue are than basic particle swarm of annual income high, which further proves the in this paper, an improved particle swarm optimization algorithm has advantages in solving the model.

By using the improved particle swarm algorithm, table 4 in the comparative analysis, under peak and off-peak electricity price, dry years income is 2.85 billion yuan, normal years income is 3.31 billion yuan, wet years income is 380 million yuan, in the system of annual earnings, dry years income is 2.81 billion yuan, normal years income is 2.77 billion yuan, wet years income is 3.28 billion yuan, the typical year in electricity price of power generation benefit is obvious higher than that of monovalent of power generation efficiency, dry years efficiency of electric power generation increased by $1.42 \%$, normal years efficiency of electric power generation increased by $19.49 \%$, wet years efficiency of electric power generation increased by $15.85 \%$. From the above analysis we can know that the optimal operation of the reservoir is different from the calculation results when considering the effect of the wet and dry season price, considering the annual electricity generation efficiency of the electricity generation price is obviously better than that of the electricity generation with the maximum power generation.

For each typical in data analysis, wet water with low price, low electricity prices is conducive to promote users to take full advantage of the dry water power, and in a certain period of time to load uniformly distributed, by wet and dry time-sharing price effectively avoid reservoir in the abundance of water loss during a large number of abandoned water electricity, reducing reservoir peak load unit investment in the dry season.

\section{Conclusion}

This paper collects the latest research results of optimal dispatching of reservoir at home and abroad on the electric power market transaction mode, analyzes the optimal operation of reservoir taking the maximum power output as the objective function of optimization target, the actual situation on the basis of the electric power market in China, established a peak and off-peak electricity price system of hydropower station under the optimal scheduling model the model is solved, and achieved good results by using the improved particle swarm algorithm, for example in Qingxi reservoir as the research object and analyze the results, obtained the largest annual income hydroelectric power generation optimal scheduling scheme, results show that the benefit of power generation of hydropower station in peak and off-peak electricity price system was significantly higher than that of a system power efficiency, improve the economic benefits of hydropower station and the optimal allocation of water resources to. There are many deficiencies in this paper, in the future research, we can also explore how to minimize the output and water consumption, make the market model of hydropower station scheduling more detailed, more suitable for the actual operation, saving the cost of power generation.

\section{References}

[1] Silvio J. Pereira-Cardenal, Birger Mo, Niels D.Riegels, Karsten Arnbjerg-Nielsen, et al. Optimization of Multipurpose Reservoir Systems Using Power Market Models [J]. Water Resour. Plann. Manage., 2015, 141(8): 04014100

[2] Jia Bin, Wang Xiuli, Wang Xifan. The price bidding mechanism and transfer price [J]. East China Electric Power, 2000 (9): 1-3.

[3] China Investment Advisory Network. Analysis of China's hydropower industry and investment consultation report in 2006[EB/OL]. http:// wxdbc.com/ newshow.asp? id=130, 2006-11-18.

[4] Guo Xiaming.Study on the regulation of water level of the reservoir at the end of the year by the time of the sub price[J]. Journal of Hydroelectric Engineering, 2004,23(3):27-30.

[5] Luo Yunxia, Wang Wanliang, Zhou Muxun. Research on the optimal operation of Cascade Hydropower Station that based on adaptive particle swarm optimization algorithm [J]. Journal of Hydroelectric Engineering, 2008, 27 (4): 7-11. 
[6] Ma Li, Li Ying, Liu Yuquan, et al. Research on some problems of Hydropower Participation in electricity market bidding [J]. Electric Power Technology Economy, 2006,18 (4) 11-14.

[7] Yao Jiangang. Discussion on the structure and mode of regional electricity market bidding [J], Power System Automation, 2003 (22): 23-26.

[8] Fang Guohua, Wu Sanchao. Research on bidding strategy of hydropower in power market environmen [J] Hydroelectric Energy Science, 2009,27 (4): 222-224.

[9] Chen Yexing, Luo Yunxia, Zhou Muxun. Resilient particle swarm optimization algorithm and its application in hydropower optimal scheduling of applications [J] Journal of Hohai University, 2010,38 (6): 604 - 607.

[10] Zhang Zhisheng, Dong Cun, Wu Xinzhen. The economic operation of hydropower system based on quantum particle swarm optimization [J]. Grid technology, 2009, 33 (18): 68-72

[11] Robert F, Cope III, David E, Dismukes and Rachelle F. Cope. Modeling Regional Electric Power Markets and Market Power.managerial and decision economics. Manage. Decis. Econ. 2001(22): 411-429.

[12] Wang Rui, Wang Liping, Jiang Shengbin, et al. Research on the market operation of hydropower in the Northwest China Power Grid [J]. Journal of Hydroelectric Engineering, 2007,33 (5): 7-9.

[13] Li Shuai, Jiang Chuanwen. The long-term optimal scheduling and risk assessment of hydropower station considering the risk of electricity price [J]. Hydropower Energy Science, 25, 2007 (3): 15-13.

[14] Lian Jijian, Ma Chao. Market bidding under short term optimal dispatching of cascade hydropower station [J] Journal of Hydroelectric Engineering, 2007,26 (4): 17-21.

[15] Kang Qingchong, Bai Lichao, Xia Qing, et al. Risk decision making of power market in the power market [J]. Chinese Journal of Electrical Engineering, 2004, 24 (8): 1-6.

[16] Wen Fushuan, David A K. Optimal co-ordinated bidding strategies in energy and ancillary service markets[J]. IEEE Proc-Gener. transm ,2002,149(3) :333-338.

[17] Krohling, R. A., L. dos Santos Coelho, Co-evolutionary particle swarm optimization using Gaussian distribution for solving constrained optimization problems. IEEE Trans. Syst., Man, Cybern. B, Cybern., 2006, 36(6): 1407-1416.

[18] Ho S.Y., Lin H.S., W.-H., Liauh S.-J., OPSO: Orthogonal particle swarm optimization and its application to task assignment problems. IEEE Trans. Syst., Man, Cybern. A, Syst., Humans, 2008, 38(2): 288-298.

[19] Dong Qianjin, Cao Guangjing, Wang Xianjia, et al. Application of particle swarm optimization algorithm in hydrology science [J]. Chinese Engineering Science, 2010, 12 (1): 80-84.

[20] LI L X, PENG H P, WANG X D, et al. An optimization method in-spired by chaotic ant behavior[J]. International Journal of Bifurcation and Chaos, 2006, (16): 2351-2364. 